Proceedings of the ASME 2009 International Design Engineering Technical Conferences \&

Design Theory and Methodology Conference

IDETC/DTM 2009

August 30 - September 2, 2009, San Diego, California, USA

DETC2009-86410

\title{
STUDY OF ALTERNATIVE STRATEGIES TO THE TASK CLARIFICATION ACTIVITY OF THE MARKET-PULL PRODUCT DEVELOPMENT PROCESS MODEL
}

\author{
Damien Motte \\ Machine Design, Lund University \\ Lund, Sweden
}

\begin{abstract}
A very large majority of the current product development process models put forward in textbooks present a homogenous structure, what Ulrich \& Eppinger [1] call the market-pull model, presented as a generic one, while other possible product development process models are merely seen as variants. This paper focuses on the task clarification and derived activities (mainly the systematic search for customer needs through market study and the supplementary development costs it entails) and investigates two alternative strategies that are not derived from the generic process model. The first alternative is the market-pull model without an extensive task clarification. The second is the application of the so-called expeditionary marketing strategy. With the help of simplified analytic modeling, the conditions for which these alternatives are as efficient as the generic process model are discussed. This advocates the development of more flexible process models.
\end{abstract}

\section{INTRODUCTION}

The current product development process models (for example Ulrich and Eppinger [1]) and associated design engineering process models (Pahl and Beitz [2], Ullman [3], Roozenburg \& Eekels [4]) have grown to become relatively homogenous. This is what Ulrich \& Eppinger [1] call the market-pull model, with emphasis on market research and systematic design, which is thought to be the generic one (hereafter called generic process model) while other models are described as variants [1, pp. 18-21].

The generic process model has been regularly challenged. First, although it is claimed to be generic, the market pull model presents several deficiencies when adapted to other product development types, particularly the technology push model (see [5] for a review). It also presents a lack of fitness between the constraints of the prescriptive design model and the descriptive, empirically observed, activities (see [6] for a review). It has also been criticized concerning the theoretical soundness of some of its grounds, mainly concerning concept generation and evaluation; see [7] for a short discussion on these issues.

This paper focuses on the tasks of the systematic search for customer needs through market study and the derived activities during development (that generates supplementary development costs). This set of tasks is called hereafter "task clarification" in reference to [2], although the derived activities are found in the other design process stages, too. The paper aims at showing that sound alternatives can be developed in that area as well. It hopes to contribute to the further development of more flexible process models. Two alternative product development strategies are considered: 1) with the first one, the generic process model is applied but the task clarification phase is basically skipped. The product is launched earlier but with a larger probability of failure. 2) The second aims at launching the product on a small scale as early as possible. In case of failure, the rework is done with much more reliable data than an early, prospective, market study. The paper compares the three cases by using a simplified analytic modeling of the product development process.

Section 2 presents the two alternative strategies and their conditions of application. Section 4 presents the framework of the study and its limitations. Sections 5 and 6 compare the strategies for routine product development (RPD) and new product development (NPD), respectively. 


\section{THE GENERIC PROCESS MODEL AND ALTERNATIVES}

The abbreviations for each strategy are $M S, \overline{M S}$ and $E M$, for the generic process model and the two alternative strategies, respectively. The first section reviews some arguments that show the limitations of going through an extensive task clarification. The second and third introduces $\overline{M S}$ and $E M$.

\subsection{Task clarification and related issues}

A product development project is always more or less risky, i.e. there is always a possibility that the project fails. Task clarification deals mainly with market uncertainty [8]. From the point of view of risk, the generic process model is built around reduction of different risks or uncertainties.

First, the generic process model aims at reducing customer uncertainty. The customer-needs specifications activities gather information on the customer; benchmarking can prevent indirectly that the customer buys the competitors' product.

However, a main issue is arises, namely market instability: the needs change during time, new competitors enter the market, new technologies appear at a fast pace, especially for high tech products (see Mohr et al. [9]). Moreover even for more mature markets, Thomke and Reinertsen [10, p. 12] report two main factors that keep the product requirements unstable and objects of changes:

- "the co-evolution of technical solutions in components that are part of a larger system;

- customers' inherent difficulty in accurately specifying their needs at the outset of a design project system."

In a survey made by these authors with more than 200 product developers, only $5 \%$ of the projects had a complete specification before beginning product design. On average, only $58 \%$ of the requirements were specified before starting the design phase.

Second, one rationale behind the generic product development process model is to "get it right the first time". This means that each project is considered in isolation. The net present value (NPV) is calculated for each project and a project starts based on a positive NPV.

Under that view, novel strategies appear: There can be alternatives to the view of a large marketing study; a company often has a product portfolio and a series of projects launched at the same periods, which can relieve the constraints of getting all product development projects right. This allows for more risky strategies (this paper, however, does not investigate the possibility of risk repartition given by a product portfolio).

The arguments in favor of the generic process models are the following:

- One argument is that this generic model is valuable for educational purposes. It helps engineering design students understand one rationale behind product development. It is indeed true that inexperienced engineering designers cope better with a procedure at hand than without one [6].

- Another argument is that a generic process model serves a positive management purpose. Cooper, one the great proponents of the Stage-Gate ${ }^{\circledR}$ model, showed on several occasions that a high quality process model is a factor of product development success. He also advocates that any process model is more to be used as a template rather than to be followed literally [11].

\subsection{The alternatives investigated}

Both alternatives are market-pull based. The process model $\overline{M S}$ corresponds to the generic process model without an extensive task clarification. Avoiding an extensive market study does not mean going into the design activity directly. There is still a need to specify the product-to-be and to get external information. But according to Tassinari [12], $60 \%$ of the specifications are usually found internally, and a good part of the remaining specifications can be found relatively quickly. In comparison, finding an exhaustive set of specifications, by using the Voice of the Customer [13], takes a very long time (see [14] for an example of application); it also involves longer development time: more specifications must be taken into account, more tests be done, etc.

The second model is called $E M$, for it implements ideas from what is sometimes called "expeditionary marketing" (see [15] and [9]). It consists in going to the market as fast as possible (on a small scale) to have a feedback on the finished product. The product can then subsequently be adapted to the real need of the customers. The main advantage of the second model is that there is a shorter development time and a smaller development cost, but this also implies a smaller probability of success. The thorough investigation recommended by the generic process model, made a long time before the product launch, can end in a "Ready. Aim. Aim. Aim." loop [16]. It is recommended, in case of NPD, to perform EMs regularly (see [9]).

One large drawback of $E M$ is that an organizational change is necessary; $E M$ projects will be more difficult to manage, at least as long as management routines are not as well established as those of the generic process model. Another important drawback is that $E M$ implies that production facilities be implemented for the small-scale product launch. Although this investment is paid back if $E M$ is successful, there is a cognitive barrier in making such investment. It should be necessary to compute the expected utility instead of the expected profit as we do below, in order to investigate whether a risk-adverse project manager would choose the EM strategy. This issue is not studied in this paper. If the company has a policy of product platforms and/or families, $E M$ becomes much easier to implement, as many of the existing manufacturing facilities may be re-used. 


\section{RELATED WORKS}

Several research works that study other alternative strategies can be found in the literature. Iansiti [8] also reports cases where the task clarification was not frozen until very late in the projects, with successful results; consequently, there have been many works on design decision postponement (e.g. $[17,18])$. Another way of minimizing such risks is to "let others go first and learn from their mistakes" [15, p. 86]. This has been an area relatively neglected by the literature, which is usually focused on innovation leaders rather than followers. A discussion can be found in [15]. An important and still largely unexplored strategy is considering testing some key features of a new product (mainly for testing technology acceptance) in a secondary market, which would avoid losses of reputation and significant market share. Many works have investigated the impact of product failure (mainly in the service area [19-21]), but few have investigated the secondary market strategy. One successful empirical case is presented in [22].

\section{THE INVESTIGATION FRAMEWORK}

First, routine product development (RPD) will be dissociated from new product development (NPD). RPD projects are projects that concern products that do not present any particular risk and for which the market is mature. Two scenarios are likely to happen: either the target sale is reached or it is not. For an RPD project, the profit will be positive in either case. In case of failure with a NPD, the outcome will be negative; consequently, the company may decide to abandon the project if estimated outcome is negative.

\subsection{Choosing among product development process models}

Choosing a product development strategy corresponds to choosing the one that yields the best profit given different risks. This corresponds to a decision model approach [23]. Under this approach, every outcome $\pi_{S, i}$ of each possible strategy $S$ is associated with a probability $p_{S, i}$. The expected profit of a strategy $S$ equals $p_{J, 1} \cdot \pi_{J, 1}+p_{J, 2} \cdot \pi_{J, 2}+\ldots+p_{J, n_{J}} \cdot \pi_{J, n_{J}}$ (in terms of utility, the $\pi_{S, i}$ s are replaced by $\left.u_{S, i} \mathrm{~s}\right)$. The decision maker has then to choose the strategy with the best-expected profit or utility.

That is not the most common approach in the product development literature reviewed in the introduction that emphasizes the articulation of some best practices (but one fully recognized one, see Ulrich and Eppinger [1, p. 13]). To base a product development process model only on profit is an oversimplification of the complex aspects of developing a product, especially its organizational aspects, but it helps in investigating the viability of alternative strategies.

The decision modeling approach also has severe limitations when used with product development strategy choice (see [24, pp. 13 and 29] for an extended discussion of the limitations of decision theory):
- First of all it makes use of probabilities of outcomes that are subjective: there are uncertainties about the risk probabilities. However, subjective probabilities are also often used when the project manager estimates the outcome of different projects within the generic process model framework.

- Also there is uncertainty about what the relevant outcomes are. In our discussion, we only discuss two possible outcomes, for tractability. The case with more options should be the object of further research.

- There are uncertainties regarding the outcomes: in product development projects, the sale forecasts are only rough estimations.

- The decision-maker is supposed to be rational, that is, consistent with his/her decisions, which is not always the case.

- Finally, reasoning in terms of expected profit or utility is presumed to yield the best outcome in the long run. However, as each product development project is different, there will be no possibility of repeating exactly the same decision.

Nevertheless, this modeling has the advantage of allowing for abstract reasoning and for gaining insights rather than being a decision support model. This is also the viewpoint adopted by Krishnan and Ulrich, who investigated design decision postponement [18, p. 315].

\section{ROUTINE PRODUCT DEVELOPMENT PROCESS 5.1 Preliminary formalization}

We will use a model conceptualization similar to [18]. As mentioned earlier, for each strategy, two outcomes are considered: either the target profit is reached, or it is not. We define $M$ the estimated gross margin of the product-to-be along the whole product lifecycle time $T_{P L C}$ for cases where the sale target is not reached. When the target is reached, the total margin is worth $M(1+\mu)$. The demand is modeled as a cumulative distribution function $F(t)$ where $F(0)=0$ and $F\left(T_{P L C}\right)=1$. The time $t$ is set at 0 for the strategy that begins the earliest. The other strategies are penalized by the margin they did not achieve under that time. Thus, for each strategy, the margin is worth $M \cdot(1+\mu) \cdot\left(F\left(T_{P L C}\right)-F\left(t_{i}\right)\right)$ for the first outcome and $M \cdot\left(F\left(T_{P L C}\right)-F\left(t_{i}\right)\right)$ for the second, $i=M S, \overline{M S}$ or $E M$. We consider the demand behavior $F$ independent of the past period of demand, that $F(t)$ is not a function of $F(t-a), F(t-2 a)$, etc. This means that if each demand $F(t)$ at $t$ for each alternative is the same. The demand not fulfilled by a late launch is not compensated. This assumption is not true for leader products in new markets or for oligopolistic situations, for example when products create the demand, but this is quite true to reality in most cases (the concept of "window of opportunity" is an illustration that the demand most often is considered exogenous to the product-to-be). 
The cost due to the development of the product is defined as $C_{d e v}$, and the manufacturing preparation cost, or ramp-up cost, is labeled $C_{R U} . C_{d e v}$ and $C_{R U}$ are considered identical for each strategy. The supplementary cost due to extensive task clarification is $C_{M S}=C_{M S}^{M S}+C_{M S}^{d e v}$, where $C_{M S}^{M S}$ is the cost due to the task clarification itself and $C_{M S}^{d e v}$ represents the supplementary workload during the other phases of the product development that this supplementary amount of information brings. $C_{E M}$ is the supplementary cost of bringing to the market quickly the product-to-be in the EM setup. $C_{E M}$ is often small. Indeed the product tested is sold with a margin that partially covers the costs of testing. Le Masson et al. [22] present such an example where the retailer had agreed upon buying the whole batch of product tested, whatever the sales results. The company could cover all costs. If the product tested does not achieve the profit target and some further rework is done, the rework cost is labeled $C_{E M}^{r e d e v} . C_{M S}^{d e v}$ and $C_{E M}^{r e d e v}$ will be considered as equivalent with the following reasoning: they correspond to the same kind of activity, that is, the supplementary workload due to information acquired from the market.

Some costs of $M S\left(C_{d e v}\right.$ and $\left.C_{R U}\right)$ and $E M\left(C_{R U}\right)$ should be less than the same costs of $\overline{M S}$ because they are postponed in time, so their present value is lower. However, for tractability reasons these will be considered equivalent.

The task clarification has two functions. First it gives supplementary information on the possible outcomes. Second, it has an impact on the development of the product itself, that is, it improves the probability of the best outcome. The first function has no impact for RPD as will be clear when the NPD case is discussed. Let $p_{M S}$ be the probability associated with the best outcome for $M S$ and $p_{\overline{M S}}$ be the probability associated with the best outcome for $\overline{M S} . \rho=p_{M S}-p_{\overline{M S}}$ corresponds to the contribution to a better outcome due to $M S$. As the development of a product under $E M$ is quite similar to $\overline{M S}$, the probabilities associated to the outcomes of $E M$ are considered the same: $p_{E M}=p_{\overline{M S}}$.

The same nomenclature will used for both RPD and NPD although the values of the different variables are not the same. For example, $\mathrm{M}$ is large and $\mu$ probably inferior to 1 , while for RPD, $M$ is small and $\mu$ largely superior to 1 .

\subsection{Strategies modeling}

The product will be developed quicker for $\overline{M S}$ than for the two other strategies, thus $t_{\overline{M S}}=0$. Equations (1) and (2) present the estimated outcomes in the case the target is or not achieved:

$$
\pi_{\overline{M S}, 1}=M \cdot(1+\mu)-C_{d e v}-C_{R U}
$$

$$
\pi_{\overline{M S}, 2}=M-C_{d e v}-C_{R U}
$$

The expected profit for $\overline{M S}$ is:

$$
\begin{aligned}
E(\pi \overline{M S})= & p \overline{M S} \cdot\left[M \cdot(1+\mu)-C_{d e v}-C_{R U}\right] \\
& +\left(1-p_{\overline{M S}}\right) \cdot\left[M-C_{d e v}-C_{R U}\right]
\end{aligned}
$$

which can be simplified into:

$$
E(\pi \overline{M S})=M \cdot(p \overline{M S} \cdot \mu+1)-C_{d e v}-C_{R U}
$$

Likewise, Eqs. (4) and (5) present the estimated outcomes for $M S$ in case the target is or not achieved:

$$
\begin{gathered}
\pi_{M S, 1}=M \cdot(1+\mu) \cdot\left(F\left(T_{P L C}\right)-F\left(t_{M S}\right)\right) \\
-C_{d e v}-C_{R U}-C_{M S} \\
\pi_{M S, 2}=M \cdot\left(F\left(T_{P L C}\right)-F\left(t_{M S}\right)\right)-C_{d e v}-C_{R U}-C_{M S}
\end{gathered}
$$

The expected profit for $M S$ is:

$$
\begin{aligned}
E\left(\pi_{M S}\right)= & M \cdot\left(p_{M S} \cdot \mu+1\right) \cdot\left(1-F\left(t_{M S}\right)\right) \\
& -C_{d e v}-C_{R U}-C_{M S}
\end{aligned}
$$

In case of success, the estimated outcome of EM is:

$$
\begin{aligned}
\pi_{E M, 1}= & M \cdot(1+\mu) \cdot\left(F\left(T_{P L C}\right)-F\left(t_{E M}\right)\right) \\
& -C_{d e v}-C_{R U}-C_{E M}
\end{aligned}
$$

In case of "failure" (target not achieved), the project manager has two choices. He/she can either rework the product in order to get a better profit, case $E M 1$, or he/she can decide to pursue with the bad variant in order not to lose time, case EM2. In case of rework, due to the great accuracy of the acquired data, it is considered that the chance of a new product failure is negligible. During the upgrade time, there is no sale of the first variant that was only produced in small quantities. Equations (8) and (9) present the estimated outcomes with rework and without, respectively:

$$
\begin{aligned}
\pi_{E M, 2}= & M \cdot(1+\mu) \cdot\left(1-F\left(t_{E M}^{r e d e v}\right)\right) \\
& -C_{d e v}-C_{R U}-C_{E M}-C_{E M}^{r e d e v} \\
\pi_{E M, 3}= & M \cdot\left(1-F\left(t_{E M}\right)\right)-C_{d e v}-C_{R U}-C_{E M}
\end{aligned}
$$

Equations (10) and (11) represent the expected profit from $E M$ in the first case $(E M 1), E\left(\pi_{E M 1}\right)$, and the second case $(E M 2)$, $E\left(\pi_{E M 2}\right)$, respectively.

$$
\begin{aligned}
& E\left(\pi_{E M I}\right)= \\
& M(\mu+1)\left[1-F\left(t_{E M}\right)-\left(1-p_{\overline{M S}}\right) \cdot\left(F\left(t_{E M}^{\text {redev }}\right)-F\left(t_{E M}\right)\right)\right] \\
& -C_{d e v}-C_{R U}-C_{E M}-\left(1-p_{\overline{M S}}\right) \cdot C_{E M}^{\text {redev }}
\end{aligned}
$$




$$
\begin{aligned}
& E\left(\pi_{E M 2}\right)= \\
& M \cdot\left(p_{\overline{M S}} \cdot \mu+1\right) \cdot\left(1-F\left(t_{E M}\right)\right)-C_{d e v}-C_{R U}-C_{E M}
\end{aligned}
$$

The expected profit of $E M$ is $E\left(\pi_{E M}\right)=\operatorname{Max}\left\{E\left(\pi_{E M 1}\right), E\left(\pi_{E M 2}\right)\right\}$.

Figure 1 represents the different strategies in the form of a decision tree. The squares represent the decision nodes and the circles the chance nodes. At each end and node is the number of the equation that represents the corresponding outcome.

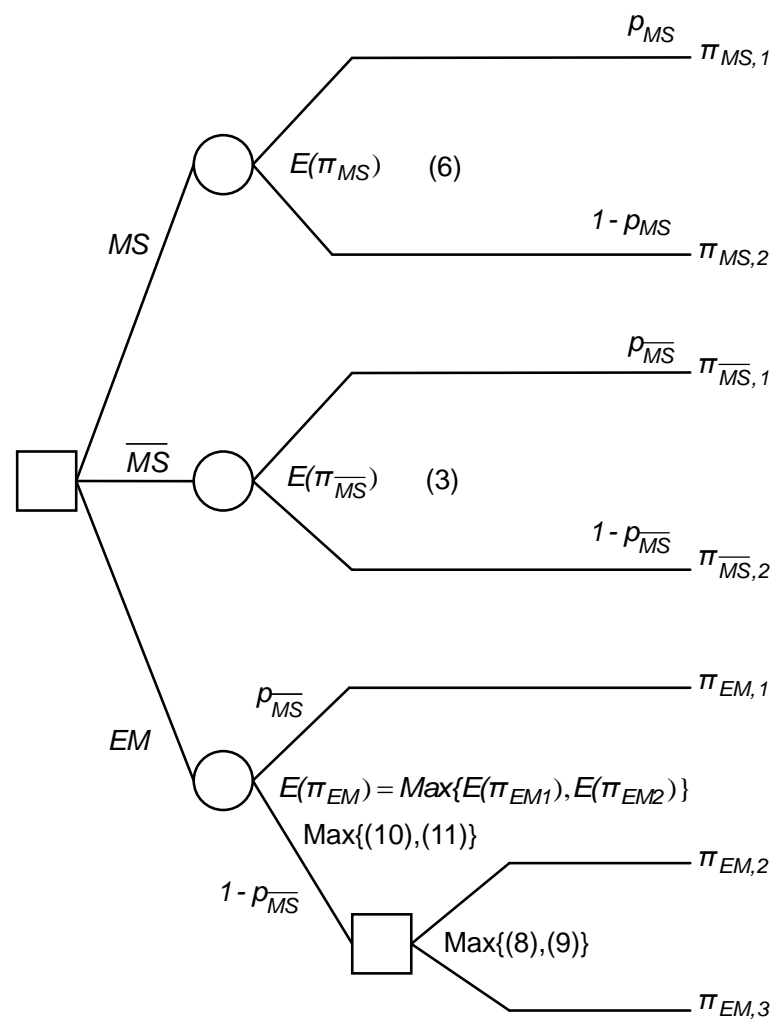

Figure 1. Decision tree for RPD

\subsection{Strategies analysis}

Comparing the different strategies comes down to comparing their expected profits. $M S$ is compared to $\overline{M S}$ and then to EMI and EM2. More specifically, we will consider the conditions for which $E\left(\pi_{M S}\right) \geq E\left(\pi_{\overline{M S}}\right), E\left(\pi_{M S}\right) \geq E\left(\pi_{E M 1}\right)$ and $E\left(\pi_{M S}\right) \geq E\left(\pi_{E M 2}\right)$ hold.

\subsubsection{Comparison between $M S$ and $\overline{M S}$}

From Eqs. (3) and (6), $E\left(\pi_{M S}\right) \geq E\left(\pi_{\overline{M S}}\right)$ is equivalent to:

$$
C_{M S}+M F\left(t_{M S}\right) \leq \rho M \mu-M p_{M S} F\left(t_{M S}\right)
$$

The terms of (12) have the following meanings. $\rho M \mu$ is the expected extra profit that will be generated if $M S$ is chosen. $M p_{M S} F\left(t_{M S}\right)$ represents the part that could not be generated between $t_{\overline{M S}}=0$ and $t_{M S}$. This gain must be superior to the costs allocated to the task clarification, $C_{M S}$, and the profit generated by $\overline{M S}$ between $t_{\overline{M S}}=0$ and $t_{M S}, M F\left(t_{M S}\right)$.

$t_{M S}$ and $\rho$ are the two parameters whose values are generated by $M S\left(p_{\overline{M S}}\right.$ and $M$ are given data, $p_{M S}$ is derived from $p_{\overline{M S}}+\rho, \mu$ is the target). If the delay between $t_{\overline{M S}}$ and $t_{M S}$ is negligible in comparison with $T_{P L C}$, and the demand distribution is relatively stable ( $F$ can be assimilated to a linear application), then the delay can be disregarded.

If time is not an issue, which is presumably the case for many RPD projects, inequality (12) becomes $C_{M S} \leq \rho M \mu$. That inequality is ordinarily verified. Let us take as an example the estimated profit for a new laptop from Dell (figures from a case study developed by Thomke et al. [25], see also [18]). The forecast total margin was $M=\$ 495$ million. $C_{d e v}$ was to be around $\$ 10$ million. Even if $\rho \mu$ was below $1 \%$ (say increase the probability by $10 \%$ of a better outcome, and increase $\mu$ by $1 \%$ ), $C_{M S}$ could go up to $\$ 495,000$, which is a large amount in comparison to $C_{d e v}$. $M$ is indeed the margin over the whole PLC; this is why $C_{M S} \leq \rho M \mu$ should be satisfied in most cases.

If time cannot be neglected (for example a window of opportunity is present) and $F\left(t_{M S}\right)$ concentrates a large part of the demand, $\overline{M S}$ can be a serious strategy to consider.

\subsubsection{Comparison between MS and EM1}

This case corresponds to the comparison of Eqs. (6) and (10). Similar to the last section, different cases can be considered.

If $F\left(t_{M S}\right), F\left(t_{E M}\right)$ and $F\left(t_{E M}^{\text {redev }}\right)-F\left(t_{E M}\right)$ are negligible in front of $F\left(T_{P L C}\right)$, then $E\left(\pi_{M S}\right) \geq E\left(\pi_{E M I}\right)$ gives (we use the fact that $C_{M S}=C_{M S}^{M S}+C_{M S}^{d e v}$ and that $C_{M S}^{d e v}$ and $C_{E M}^{\text {redev }}$ are considered as equivalent, $c f$. section 5.1):

$$
C_{M S}^{M S} \leq-M \mu \cdot\left(1-p_{M S}\right)-p_{\overline{M S}} C_{E M}^{r e d e v}+C_{E M}
$$

This condition will not hold in general. The first two terms on the right are negative. $\left(1-p_{M S}\right) \cdot M \mu$ usually has a large value. Moreover, as mentioned in section 5.1, $C_{E M}$ is often very small.

When time matters, $t_{M S}, t_{E M}$ and $\left(t_{E M}^{\text {redev }}-t_{E M}\right)$ can be considered as having the same order of magnitude: it may take for example 3 to 6 months to make a thorough market study and work with those data. It can take a similar amount of time to produce a batch of the developed product and test it on the market - and again 3 to 6 months in case of rework $\left(t_{E M}^{\text {redev }}-t_{E M}\right)$. In RPD, the demand may be considered as roughly linear. In that case, with

$$
\begin{gathered}
t_{M S} \approx t_{E M} \approx t_{E M}^{r e d e v}-t_{E M} \approx t, E\left(\pi_{M S}\right) \geq E\left(\pi_{E M I}\right) \text { gives: } \\
C_{M S}^{M S} \leq-M\left[\left(1-p_{M S}\right) \mu+\left(p_{\overline{M S}}-1-\rho \mu\right) F(t)\right] \\
\quad-p_{\overline{M S}} C_{E M}^{r e d e v}+C_{E M}
\end{gathered}
$$


The term $\rho \mu$ is negligible compared to $p_{\overline{M S}}-1$. This gives:

$$
\begin{aligned}
C_{M S}^{M S} \leq & M F(t)\left(1-p_{\overline{M S}}\right)-M \mu\left(1-p_{M S}\right) \\
& -p_{\overline{M S}} C_{E M}^{r e d e v}+C_{E M}
\end{aligned}
$$

Compared to (13), a term has been added to the left-hand side of (15). It corresponds to the loss of margin of the EMI strategy due to rework. For that case, either $M S$ or $E M 1$ can be recommended; it all depends of the value of $F(t)\left(1-p_{\overline{M S}}\right)$ versus $\mu\left(1-p_{M S}\right)$.

Finally, no general recommendation can be made for the nonlinear case.

\subsubsection{Comparison between MS and EM2}

The second case is the comparison of Eqs. (6) and (11).

If $F\left(t_{M S}\right)$ and $F\left(t_{E M}\right)$ are negligible in front of $F\left(T_{P L C}\right)$, then $E\left(\pi_{M S}\right) \geq E\left(\pi_{E M I}\right)$ can be reduced to:

$$
C_{M S} \leq C_{E M}+M \rho
$$

$M \rho$ is usually larger than $C_{M S}$ (cf. section 5.1). In that case $M S$ is to be preferred to $E M 2$. If $F\left(t_{M S}\right)$ and $F\left(t_{E M}\right)$ are not negligible and, as devised above, they can be considered as equivalent, (16) becomes:

$$
C_{M S} \leq C_{E M}+M \rho \cdot(1-F(t))
$$

Yet in that case it is likely that the term including $M \rho$ will still be very large. In that case too, $M S$ should generally be preferred to $E M 2$.

Again, no general recommendation can be made for the nonlinear case.

\subsubsection{Summary}

Table 1 summarizes the results of the analysis.

Table 1. Comparisons for RPD

\begin{tabular}{ll}
\hline Comparison & \\
\hline$M S$ vs. $\overline{M S}$ & $\begin{array}{l}\text { Unless } \mu \text { and } \rho \text { are small and/or there is a } \\
\text { windows of opportunity, the gain made by an } \\
\text { earlier launch does not compensate the loss of } \\
\text { poorer probability of success. }\end{array}$
\end{tabular}

$M S$ vs. EMI EMI is preferable if the demand distribution at the beginning of sales is negligible in front of $T_{P L C}$. Otherwise there is no general possible recommendation.

$M S$ vs. EM2 MS is recommended.

\section{NEW PRODUCT DEVELOPMENT \\ 6.1 Preliminary formalization}

A new product development project involves, in case of failure, a risk of negative return. In that case the project manager always has the possibility to abandon the project. The margin $M$ is very small and $\mu$ is largely superior to 1 , while it was merely considered inferior to 1 in RPD. $p_{\overline{M S}}$ is considered to be very low. The new decision tree that is discussed in this section 6 is represented in Fig. 2. It was mentioned in section 5.1 that the $M S$ strategy had two effects: beyond enhancing the probability of success (with $\rho$ ), it also gives first hand information on this success after the market study is performed. Unlike $\overline{M S}, M S$ has the option to stop after the market study, while in the first case the project manager needs to make that decision right from the start.

As the market study is performed early in the process and the market behavior is relatively difficult to define in case of NPD, the $M S$ information is imperfect. There are cases where a predicted success turned into a failure and vice-versa. That means that for a given project, after it has been estimated that the project will be successful with a probability $p_{M S}$, the project can still fail, and vice-versa. This is represented at nodes $\mathrm{H}$ and I Fig. 2. Thus $p_{M S}$ (prior subjective probability of success or $p(M(1+\mu)))$ must be corrected for this inaccuracy (the corrected probability is named $p_{M S^{+}}$. Moreover the conditional probabilities at nodes $\mathrm{H}$ and I must be determined.

There is a mechanism in decision theory that describes how to deal with imperfect information [23]. The frequencies of predicted success turned into a failure and vice-versa can be gathered in a table like Table 2. They can be obtained by studying the outcomes of previous projects. With the prior probability $p_{M S}$ and the conditional probabilities in Table 2, $p_{M S^{+}}$and $p_{M S^{-}}$can now be determined:

$$
\begin{aligned}
& p_{M S^{+}}=p\left(M S^{+} \mid M(1+\mu)\right) \cdot p_{M S^{+}}+p\left(M S^{+} \mid M\right) \cdot\left(1-p_{M S}\right) \\
& p_{M S^{-}}=p\left(M S^{-}, \mid M(1+\mu)\right) \cdot p_{M S}+p(M S \mid M) \cdot\left(1-p_{M S}\right)
\end{aligned}
$$

Finally, the probabilities at nodes $\mathrm{H}$ and I (see Fig. 2) can be computed. They correspond to the conditional probability of each outcome given $M S^{+}$and $M S^{-}$, respectively. The first probability at node $\mathrm{H}, p\left(M(1+\mu) \mid M S^{+}\right)$is equal to:

$$
p\left(M(1+\mu) \mid M S^{+}\right)=\frac{p\left(M S^{+} \mid M(1+\mu)\right) \cdot p_{M S}}{p_{M S^{+}}}
$$

The other probabilities follow the same pattern. 
Table 2. Conditional probability of MS predictions actual product success or failure

\begin{tabular}{lcc} 
prediction & $M(1+\mu)$ & $M$ \\
\hline positive $M S^{+}$ & $p\left(M S^{+} \mid M(1+\mu)\right)$ & $p\left(M S^{+} \mid M\right)$ \\
negative $M S^{-}$ & $p\left(M S^{-} \mid M(1+\mu)\right)$ & $p\left(M S^{-} \mid M\right)$ \\
\hline
\end{tabular}

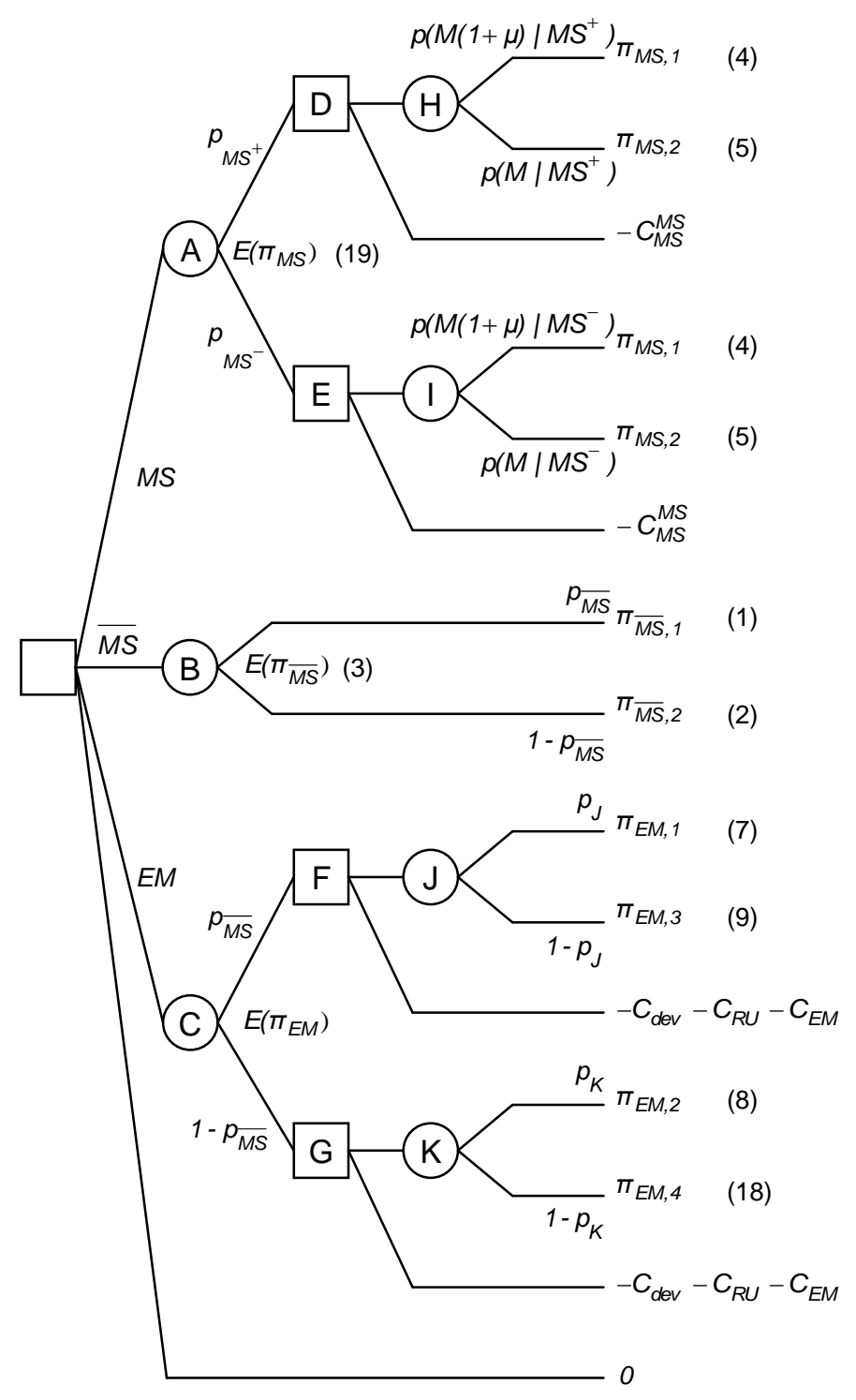

Figure 2. Decision tree for NPD

In the RPD framework, the decision maker did not have to consider the decision to abandon (nodes $\mathrm{D}$ and $\mathrm{E}$ ). Thus the expected outcome for $M S$ becomes:

$$
\begin{aligned}
E\left(\pi_{M S}\right)= & p_{M S^{+}} \cdot p\left(M(1+\mu) \mid M S^{+}\right) \cdot \pi_{M S, 1}+p_{M S^{+}} \cdot p\left(M \mid M S^{+}\right) \cdot \pi_{M S, 2}+ \\
& p_{M S^{-}} \cdot p\left(M(1+\mu) \mid M S^{+}\right) \cdot \pi_{M S, 1}+p_{M S^{-}} \cdot p\left(M \mid M S^{+}\right) \cdot \pi_{M S, 2} \\
= & {\left[p\left(M S^{+} \mid M(1+\mu)\right) \cdot p_{M S}+p\left(M S^{-} \mid M(1+\mu)\right) \cdot p_{M S}\right] \cdot \pi_{M S, 1}+} \\
& {\left[p\left(M S^{-} \mid M\right) \cdot\left(1-p_{M S}\right)+p\left(M S^{-} \mid M\right) \cdot\left(1-p_{M S}\right)\right] \cdot \pi_{M S, 2} } \\
= & p_{M S} \cdot \pi_{M S, 1}+\left(1-p_{M S}\right) \cdot \pi_{M S, 2}
\end{aligned}
$$

which corresponds to the expected outcome in the RPD case.

For $E M$ the case is different. The product is developed before any choice is made. Then, in case of bad response, the project manager can decide to rework the product or to abandon it, but in case of good response, the product is launched without rework. Although the representations of $M S$ and $E M$ in the decision tree (Fig. 2) are similar, they correspond to different decision processes. In case of good response, the probability $1-p_{J}$ of further failure should be very small, only due to market changes between the small-scale launch and full-scale launch. It can be therefore neglected. It will thus be considered hereafter that the branch of probability $p_{\overline{M S}}$ leaving node $\mathrm{C}$ will consist only in the outcome represented by Eq. (7) (nodes J and F are removed).

\subsection{Strategies modeling}

The equations describing the outcomes for the cases where the product is developed are the same as in section 5.2, except for the $E M$ case where the product is reworked but fails due to the large market variations.

$$
\pi_{E M, 4}=M \cdot\left(1-F\left(t_{E M}^{\text {redev }}\right)\right)-C_{d e v}-C_{R U}-C_{E M}-C_{E M}^{\text {redev }}
$$

For the cases where the product development is abandoned, the outcomes are:

- $\quad$ Strategy $M S:-C_{M S}^{M S}$

- Strategy $E M:-C_{d e v}-C_{R U}-C_{E M}$

- Decision to not develop a product: 0

There are theoretically $2^{2}$ cases to investigate for $M S$. Let $H$ be the expected outcome at node $\mathrm{H}$ and $I$ the expected outcome at node I. At node $\mathrm{D}$, the decision maker will choose $\operatorname{Max}\left\{H,-C_{M S}^{M S}\right\}$ and at node $\mathrm{E}, \operatorname{Max}\left\{I,-C_{M S}^{M S}\right\}$. Only the most likely case is of interest, that is, when the outcome $H$ is chosen at node $\mathrm{H}$ and $-C_{M S}^{M S}$ at node $\mathrm{I}$. The expected outcome at node $\mathrm{H}$ is of the same form as (6), with the probability $p_{M S}$ substituted with $p\left(M(1+\mu) \mid M S^{+}\right)$. The expected profit $E\left(\pi_{M S}\right)$, node $\mathrm{A}$, is:

$$
\begin{aligned}
& E\left(\pi_{M S}\right)= \\
& p_{M S^{+}}\left[M \cdot\left(p\left(M(1+\mu) \mid M S^{+}\right) \cdot \mu+1\right) \cdot\left(1-F\left(t_{M S}\right)\right)\right. \\
& \left.-C_{d e v}-C_{R U}-C_{M S}\right]-p_{M S^{-}} \cdot C_{M S}^{M S}
\end{aligned}
$$


The formulation of the expected profit for $\overline{M S}, E(\pi \overline{M S})$, node $\mathrm{B}$, is the same for RPD and NPD, and is defined in Eq. (3).

Finally, there are also $2^{2}$ theoretical cases to investigate for $E M$, of which the one of interest is that for which the decision maker decides at both nodes $F$ and $G$ to develop the product. The formulation of $E\left(\pi_{E M}\right)$ is tedious and will not be used as is, so it is not reproduced here.

\subsection{Strategies analysis}

\subsubsection{Comparison between $M S$ and $\overline{M S}$}

It is easier to compare the costs and the gross profits separately than to consider the two expected profits simultaneously.

From Eqs. (3), $E\left(\pi_{M S}\right)$ and (19), $E\left(\pi_{\overline{M S}}\right)$, inequality (20) shows the necessary condition for costs generated with $M S$ being inferior to those generated with $\overline{M S}$.

$$
C_{M S}^{M S}+p_{M S^{+}} \cdot C_{M S}^{d e v}<\left(1-p_{M S^{+}}\right) \cdot\left(C_{d e v}+C_{R U}\right)
$$

This condition will almost always hold. The left member of the inequality (20) is inferior to $C_{M S}\left(C_{M S}=C_{M S}^{M S}+C_{M S}^{d e v}\right)$. It would be unreasonable for $C_{M S}$ to be, say, more than $20 \%$ of both $C_{d e v}$ and $C_{R U}$; and $p_{M S^{+}}$is unlikely to ever being that high. It would require either a very accurate market forecast for this project (unlikely for new projects) and/or the company would have both a very accurate forecast history in case of successes (i.e. $p\left(M S^{+} \mid M(1+\mu)\right)$ very high), and a very bad forecast history in case of failures $\left(p\left(M S^{+} \mid M\right)\right.$ very low, that is, $p\left(M S^{+} \mid M\right)$ very high, see section 6.1).

The gross profit part of Eq. (19) can be rewritten in this way:

$$
M \cdot\left(p_{M S} \cdot p\left(M S^{+} \mid M(1+\mu)\right) \cdot \mu+p_{M S^{+}}\right) \cdot\left(1-F\left(t_{M S}\right)\right)
$$

and is compared to $M \cdot\left(p_{\overline{M S}} \cdot \mu+1\right)$. We first consider $F\left(t_{M S}\right)$ negligible against 1 . We first compare $p_{M S} \cdot p\left(M S^{+} \mid M(1+\mu)\right)$ with $p_{\overline{M S}}$. The condition for the former to be superior to the latter is:

$$
p_{M S}<\frac{\rho}{1-p\left(M S^{+} \mid M(1+\mu)\right)}
$$

The denominator represents the frequency of the company's market studies where the product has been predicted as successful but has subsequently been a failure (see Table 2). This probability should be lower than $\rho$ most of the time, which means that condition (22) will hold most of the time.

Each $p_{M S} \cdot p\left(M S^{+} \mid M(1+\mu)\right)$ is higher than $p_{\overline{M S}}$, and this difference is amplified $\mu$ times $(\mu>1)$. Thus although $p_{M S^{+}}$is always inferior to 1 , once $p_{M S} \cdot p\left(M S^{+} \mid M(1+\mu)\right)>p_{M S^{+}}$, then Eq. (21) is superior to $M \cdot\left(p_{\overline{M S}} \cdot \mu+1\right)$.

If the time aspect cannot be neglected (window of opportunity), the choice of the adequate strategy will depend on the data of the specific project.

\subsubsection{Comparison between MS and EM}

In this case too, the gross profits and the costs will be compared separately.

As in section 5.3.2, $t_{M S}$ and $t_{E M}$ will be considered as having the same order of magnitude and set to $t$. The gross profit term in case of failure for $E M$, see Eq. (18) will be neglected. The gross profit at node $\mathrm{C}$, after suitable transformation, is equal to:

$$
\begin{gathered}
M \cdot(\mu+1) \cdot\left(p \frac{\overline{M S}}{+}(1-p \overline{M S}) \cdot p_{K}\right) \cdot(1-F(t)) \\
-M \cdot(\mu+1) \cdot\left(1-p_{\overline{M S}}\right) \cdot\left(F\left(t_{E M}^{r e d e v}\right)-F(t)\right)
\end{gathered}
$$

The negative term, due to the delay in case of rework, will be considered neglected at first. This term's significance depends on whether the product launch time is important or not. What remains to be compared are the following terms: $p_{M S} \cdot p\left(M S^{+} \mid M(1+\mu)\right)$ and $p \overline{M S}+(1-p \overline{M S}) \cdot p_{K}$. We need to introduce a new variable to characterize $p_{K} . p_{K}$ is the probability of success of a rework after the small-scale launch has failed. With more reliable information than with a market study, $p_{K}$ is thus superior to $p_{M S}$. We formalize that affirmation into $p_{K}=p_{M S}+\rho$ ' by analogy with $\rho$. We put $p\left(M S^{+} \mid M(1+\mu)\right)=1$ (prefect market study prediction in the past) and we obtain the following condition: the gross profit of $S M$ is superior to the gross profit of EM iff:

$$
-p_{M S}^{2}+p_{M S} \cdot\left(1+\rho-\rho^{\prime}\right)-\rho+\rho^{\prime}+\rho \rho^{\prime}<0
$$

We know that $p_{M S}$ is bounded between $\rho$ and 1 . It can be shown that the first root to this polynomial term is always above 1 , and the second root always under 0 for $\rho^{\prime}>\rho$ or inferior to $\rho$ for $\rho>\rho$ '. Between the two roots, the polynomial term is positive. This means that EM always gives better gross profits than $S M$. A sensitivity analysis was performed with $\rho$ and $\rho$ ' varying between 0 and 0.4 , and $p_{M S}$ between 0.1 and 0.5 . The gross profit for $S M$ represented between 0.25 and 0.75 of that of $E M$. If $p\left(M S^{+} \mid M(1+\mu)\right)<1$ the ratio is multiplied by $p\left(M S^{+} \mid M(1+\mu)\right)$, which implies an even larger difference. This compensates largely for the negative term neglected in (23).

The costs of $E M$ are, on the other hand, always larger than $M S$ 's. They amount to:

$$
C_{d e v}+C_{R U}+C_{E M}+\left(1-p \frac{}{M S}\right) \cdot C_{E M}^{r e d e v}
$$

If the costs are small in comparison to the gross profit, $E M$ is to be preferred. Otherwise, especially if the market study results are apparently good, it is necessary to consider both options in 
greater detail. The main result for this comparison is that there is no case where $M S$ can be generally recommended rather than $E M$ for NPD.

\subsubsection{Summary}

Table 3 summarizes the results of the analysis.

Table 3. Comparisons for NPD

\section{Comparison}

$M S$ vs. $\overline{M S}$ If the time aspect can be neglected, $M S$ is recommended.

$M S$ vs. EM EM is to be recommended, given that costs are small in comparison to the gross profit.

\section{CONCLUSION}

In this paper, three strategies were investigated, $M S, \overline{M S}$ and $E M$. The alternative strategies were chosen because they showed that trying to reduce consumer uncertainty by making a thorough but early investigation is not always the best solution: Under RPD, if the market is mature, or if there is a window of opportunity, $\overline{M S}$ can be recommended; If time is not a problem, EM1 is also an option; Under NPD, EM is theoretically best suited in most cases.

These alternatives are not easy to implement. They require a very flexible organization. In that area, there is a growing body of literature concerning agile project development organization and methods (see e.g. [26]). Stemming from software development, it emphasizes among other things the developtest-adapt loop, regardless of the level of development of the product. This helps both to correct early the technical shortcomings, and to allow for a more accurate picture of the customer needs throughout the product development. These methods could be combined with EM. A first simplified model of agile product development would be identical to $M S$, with the costs of testing in $C_{M S}$. However, $p_{M S}$ would be much higher. There is a clear need for empirical studies for performing this comparison.

There are some severe restrictions in using a simplified analytic model based on decision trees, but it is necessary for tractability and for a good insight, as this paper has shown.

The analytical model is not suitable for the study of additional behaviors: the study of the impact of a product failure, first launch in a secondary market, the risk distribution across portfolio. For these, analytical models must be discretized along time periods. This should be the object of future work. The model is suitable (with some loss of precision) to NPV calculation, but is not adapted to real options analysis (ROA). Decision trees will be important to take into account the volatility of the different options. The main difference compared to NPV is that the discount rate is dependent on each decision and risk (see [27]), which changes the rules for defining the best strategies (if the discount rates vary largely).

Finally, the utility of the risk-adverse decision maker has not been investigated. This is an important parameter in the preliminary investigation of any alternative strategy, as it facilitates representing how the decision maker is likely to behave when faced with multiple choices under risk. This will be the object of further study.

\section{NOMENCLATURE AND ABBREVIATIONS}

$E M \quad$ product development with expeditionary marketing strategy

$M S \quad$ product development with extensive task clarification

$\overline{M S}$ product development without extensive task clarification

$N P D$ new product development

$R P D$ routine product development

$C_{d e v} \quad$ product development cost

$C_{E M} \quad$ supplementary cost due to $E M$.

$C_{E M}^{r e d e v}$ rework cost in case of failure in the EM setup

$C_{M S} \quad$ extensive task clarification cost

$C_{M S}^{M S} \quad$ cost due to the task clarification itself

$C_{M S}^{d e v} \quad$ supplementary workload due to $M S$ in other PD phases

$C_{R U} \quad$ manufacturing preparation costs (aka ramp-up cost)

$F(t) \quad$ Cumulative distribution function of the demand

$M \quad$ Gross margin of the product along $T_{P L C}$

$T_{P L C}$ product lifecycle time

$\mu \quad$ relative gross margin increase in case of success

$\pi \quad$ profit

$\rho \quad$ difference between the probability of success of strategy $M S$ and the probability of success of $\overline{M S}$

\section{REFERENCES}

[1] Ulrich, K. T. and Eppinger, S. D., 2008, Product Design and Development, $4^{\text {th }}$ Edition, McGraw-Hill, London.

[2] Pahl, G., Beitz, W., Feldhusen, J. and Grote, K.-H., 2007, Engineering Design - A Systematic Approach, $3^{\text {rd }}$ Edition, Springer, London.

[3] Ullman, D. G., 1997, The Mechanical Design Process, $2^{\text {nd }}$ Edition, McGraw-Hill, Singapore.

[4] Roozenburg, N. F. M. and Eekels, J., 1995, Product Design: Fundamentals and Methods, Wiley, Chichester.

[5] Bishop, G. L. and Magleby, S. P., 2004, "Review of Technology Push Product Development Models and 
Processes", 16th International Conference on Design Theory and Methodology - DETC/DTM'04 (September 28October 2, 2004), Salt Lake City, UT.

[6] Bender, B., 2004, Successful Individual Design Process Strategies in the Earlier Phases of Product Development (In German. Original Title: Erfolgreiche individuelle Vorgehensstrategien in frühen Phasen der Produktentwicklung), PhD Thesis, Fortschritt-Berichte VDI (Reihe 1, Nr. 377), Fakultät für Verkehrs- und Maschinensysteme, TU Berlin, Berlin.

[7] Motte, D., 2008, "A review of the fundamentals of systematic engineering design process models", 10th International Design Conference DESIGN 2008, DS 48, Vol. 1, (May 19-22, 2008), Design Society, pp. 199-210.

[8] Iansiti, M., 1995, "Shooting the rapids: Managing product development in turbulent environments", California Management Review, Vol. 38 (1), p. 37.

[9] Mohr, J., Sengupta, S. and Slater, S., 2005, Marketing of high-technology products and innovations, $2^{\text {nd }}$ Edition, Prentice Hall, Upper Saddle River, NJ.

[10] Thomke, S. and Reinertsen, D., 1998, "Agile product development: Managing development flexibility in uncertain environments", California Management Review, Vol. 41 (1), pp. 8-30.

[11] Cooper, R. G. and Kleinschmidt, E. J., 2007, "Winning businesses in product development: the critical success factors", Research Technology Management, Vol. 50 (3), pp. 52-66.

[12] Tassinari, R., 1995, Functional Analysis (In French. Original title: L'analyse fonctionnelle), AFNOR, Paris.

[13] Griffin, A. and Hauser, J. R., 1993, "The Voice of the Customer", Marketing Science, Vol. 12 (1), pp. 1-27.

[14] Griffin, A., 1989, Functionally integrating new product development, $\mathrm{PhD}$ Thesis, Sloan School of Management, MIT, Cambridge.

[15] Hamel, G. and Prahalad, C. K., 1991, "Corporate Imagination and Expeditionary Marketing", Harvard Business Review, Vol. 69 (4), pp. 81-93.

[16] MacDonald, E. and Lublin, J., 1998, "Management: In the Debris of a Failed Merger: Trade Secrets", Wall Street Journal, March 10, 1998, p. B1.
[17] Gil, N., Tommelein, I. D. and Beckman, S., 2004, "Postponing design processes in unpredictable environments", Research in Engineering Design, Vol. 15 (3), pp. 139-154.

[18] Krishnan, V. and Bhattacharya, S., 2002, "Technology Selection and Commitment in New Product Development: The Role of Uncertainty and Design Flexibility", Management Science, Vol. 48 (3), pp. 313-327.

[19] Kalamas, M., Laroche, M. and Makdessian, L., 2008, "Reaching the boiling point: Consumers' negative affective reactions to firm-attributed service failures", Journal of Business Research, Vol. 61 (8), pp. 813-824.

[20] Westbrook, R. A., 1987, "Product-consumption-based affective responses and postpurchase processes", JMR, Journal of Marketing Research, Vol. 24 (3), pp. 258-271.

[21] Folkes, V. S., 1984, "Consumer Reactions to Product Failure: An Attributional Approach", Journal of Consumer Research, Vol. 10 (4), pp. 398-410.

[22] Le Masson, P., Weil, B. and Hatchuel, A., 2006, Innovation Processes - Innovation Engineering Design and Corporate Growth (In French. Original title: Les processus d'innovation - conception innovante et croissance des entreprises), Hermès-Lavoisier, Paris.

[23] French, S., 1986, Decision theory: An Introduction to the Mathematics of Rationality, Ellis Horwood; Chichester .

[24] Hansson, S. O., 1991, An overview of decision theory, National Board for Spent Nuclear Fuel (Statens kärnbränslenämnd - SKN), Stockholm.

[25] Thomke, S., Krishnan, V. and Nimgade, A., 1998, Product development at Dell Computer Corporation, Harvard Business School Case, Boston, MA.

[26] Highsmith, J. A., 2004, Agile project management : creating innovative products, Addison-Wesley, Boston, MA.

[27] Copeland, T. and Antikarov, V., 2003, Real Options: A Practitioner's Guide, Texere, London. 